\title{
Absorption of Bound States in Hot, Dense Matter
}

R. Shepherd, P. Audebert, C. Chenais-Popovics, J.P. Geindre, M. Fajardo, C. Iglesias, S. Moon, F. Rogers, J.C. Gauthier and P. Springer

This article was submitted to $9^{\text {th }}$ International Workshop on Radiative Properties of Hot Dense Matter, Santa Barbara, California, October 29 - November 2, 2000

\section{March 6, 2001}

U.S. Department of Energy

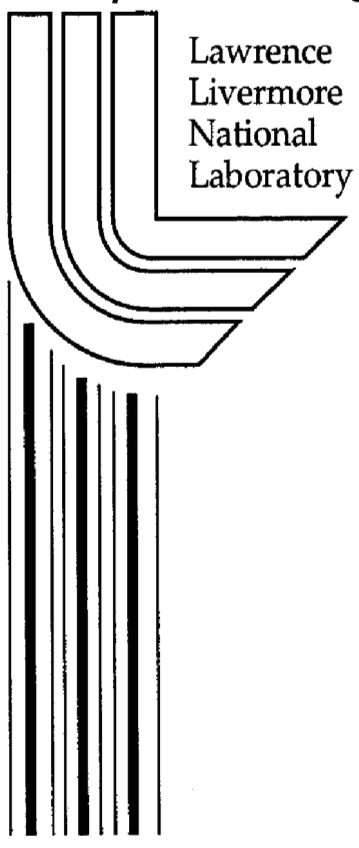




\section{DISCLAIMER}

This document was prepared as an account of work sponsored by an agency of the United States Government. Neither the United States Government nor the University of California nor any of their employees, makes any warranty, express or implied, or assumes any legal liability or responsibility for the accuracy, completeness, or usefulness of any information, apparatus, product, or process disclosed, or represents that its use would not infringe privately owned rights. Reference herein to any specific commercial product, process, or service by trade name, trademark, manufacturer, or otherwise, does not necessarily constitute or imply its endorsement, recommendation, or favoring by the United States Government or the University of California. The views and opinions of authors expressed herein do not necessarily state or reflect those of the United States Government or the University of California, and shall not be used for advertising or product endorsement purposes.

This is a preprint of a paper intended for publication in a journal or proceedings. Since changes may be made before publication, this preprint is made available with the understanding that it will not be cited or reproduced without the permission of the author.

This report has been reproduced directly from the best available copy.

Available electronically at http://www.doc.gov/bridge

Available for a processing fee to U.S. Department of Energy

And its contractors in paper from

U.S. Department of Energy

Office of Scientific and Technical Information

P.O. Box 62

Oak Ridge, TN 37831-0062

Telephone: (865) 576-8401

Facsimile: (865) 576-5728

E-mail: reports@adonis.osti.gov

Available for the sale to the public from

U.S. Department of Commerce

National Technical Information Service

5285 Port Royal Road

Springfield, VA 22161

Telephone: (800) 553-6847

Facsimile: (703) 605-6900

E-mail: orders@ntis.fedworld.gov

Online ordering: http:/ / www.ntis.gov/ordering.htm

\section{OR}

Lawrence Livermore National Laboratory

Technical Information Department's Digital Library

http: / / www.llnl.gov/tid/Library.html 


\title{
Absorption of bound states in hot, dense matter
}

\author{
Ronnie Shepherd ${ }^{\mathrm{a}, *}$, P. Audebert ${ }^{\mathrm{b}}$, C. Chenais-Popovics ${ }^{\mathrm{b}}$, \\ J. P. Geindre ${ }^{b}$, M. Fajardo ${ }^{1}$, C. Iglesias ${ }^{a}$, S. Moon ${ }^{a}$, \\ F. Rogers ${ }^{a}$, J.C. Gauthier ${ }^{b}$, P. Springer ${ }^{a}$ \\ a Physics and Advanced Technologies, \\ Lawrence Livermore National Laboratory, \\ P.O. 808, Livermore Ca., USA,94550. \\ b Laboratoire pour l'Utilisation des Lasers Intenses, UMR7605, \\ CNRS - CEA - Université Paris VI - École polytechnique, \\ 91128 Palaiseau, France
}

\begin{abstract}
Preliminary experiments using a long pulse laser generated $\mathrm{X}$-ray source to backlight a short pulse laser heated thin foil have been performed at the Laboratoire pour l'Utilisation des Lasers Intenses (LULI) at Ecole Polytechnique in France. In these experiment, a $2 \mathrm{~J}, 300 \mathrm{ps}, 532 \mathrm{~nm}$ laser was used to create the X-ray back-lighter. The primary diagnostic was a von Hamòs spectrograph coupled to a 500 fs X-ray streak camera (TREX-VHS) developed at LLNL . This diagnostic combines high collection efficiency $\left(\approx 10^{-4}\right.$ steradians) with fast temporal response $(\approx$ $500 \mathrm{fs}$ ), allowing resolution of extremely transient spectral variations. The TREXVHS was used to determine the time history, intensity, and spectral content of the back-lighter. The second diagnostic, Fourier Domain Interferometry (FDI), provides information about the position of the critical density of the target and thus the expansion hydrodynamics, laying the ground work for the plasma characterization. The plasmas were determined to be moderately to strongly coupled, resulting in absorption measurements that provide insight into bound states under such conditions.
\end{abstract}

Key words: Strongly coupled plasma, opacity, short pulse laser

\footnotetext{
* Corresponding author. shepherd1@llnl.gov

1 Also with: Grupo de Lasers e Plasmas, Instituto Superior Técnico, 1 Avenida Rovisco Pais, Lisboa, Portugal
} 


\section{Introduction}

The development of high intensity, short pulse lasers offer a new way to study high energy-density plasmas[1]. When short pulse, $<1 \mathrm{ps}$, lasers with intensities in the range of $10^{15}$ to $10^{16} \mathrm{~W} / \mathrm{cm}^{2}$ are used to illuminate solid targets impulse heating followed by rapid heat conduction produces a high density, high temperature plasma with little hydrodynamic expansion. Although transient, the plasma parameters generated by heating solids with short pulse lasers can result in physical states that are difficult to achieve using other techniques. In these plasmas, the temperature is relatively low $(<100 \mathrm{eV})$ while the density remains its initiai value, in the present case close to solid. The result is a state where the interparticle shielding becomes insufficient to neutralize the charge of the individual ions, a state that can be characterized by the dimensionless parameter $\Gamma_{i i}$. It is defined as the ratio of the particle potential energy to the kinetic energy,

$$
\Gamma_{i i} \equiv \frac{\langle\text { Potential Energy }\rangle}{\langle\text { Kinetic Energy }\rangle}=\frac{\bar{Z}^{2} e^{2}}{r_{i} K_{B} T} ; r_{i}=\left(\frac{3}{4 \pi N_{i}}\right)^{1 / 3} .
$$

where $\bar{Z}$ is the average charge state, $T$ the electron temperature and $N_{i}$ the ion density. When $\Gamma_{i i}$ approaches 1 the ions become correlated and the bound states begin to overlap in such a way that it is difficult to predict ionization balance. Using absorption spectroscopy, one can infer the ionization balance in the plasma and compare these measurements to code predictions. Further, the detailed shape of the absorption features provide information about the effects of contiuum lowering and collisional broadening of upper states that are partially filled.

$\mathrm{X}$-ray and laser heated targets have been used for studying bound state absorption in hot, dense plasmas in the past[4][5][6]. Additionally, recent experiments have utilized ultra short pulse lasers for point-projection spectroscopy of expanding plasmas, providing space and time resolved ionformation on the average ionization[7]. These experiments have shown a need for experimental data to test complex absorption theories used to model radiation transport. Here we report on a new experimental technique to study the ionization balance in dense, moderate to strongly coupled plasmas. The technique uses an ultra short pulse laser to create a thin, high-density plasma slab fairly uniform in density and temperature. A temporally long X-ray pulse is used to backlight the slab and the time resolved absorption spectra is gathered with an X-ray streak camera. The plasma characteristics were inferred from Fourier Domain Interferometry (FDI) measurements of the expansion velocity of the critical surface. The measured expansion velocity was compared to simulations to extract the plasma parameters. We show results from a proof of principle experiment. The experiment demonstrates the ability to measure absorption 
potassium hydrogen phthalate (KAP) crystal interfaced to a fast X-ray streak camera arranged in the von Hamòs geometry[11]. The X-rays emitted from the samarium back-lighter were focused into the $25.4 \mathrm{~mm}$ long, $120 \mu \mathrm{m}$ wide slit of the X-ray streak camera. The spectral coverage was from $7.4 \AA$ to $8.4 \AA$, looking at the $\mathrm{K}_{\alpha}$ aluminum absorption features between the He-like and $\mathrm{F}$ like ions. The signal brightness was increased with an image intensifier and displayed using a fiber optic coupled, $1024 \times 1024$ CCD camera. Assuming a $150 \mu \mathrm{m}$ upper bound on the swept spatial resolution, the spectral resolution was estimated to be $0.006 \AA$ providing a resolving power of $E / \Delta E=1200-1400$. The streak camera used in the experiment had a $500 \mathrm{fs}$ temporal resolution and was operated with a sweep-speed of $1.42 \mathrm{ps} / \mathrm{mm}$, resulting in $36 \mathrm{ps}$ of temporal data per shot. As indicated in Fig. 1, the back-lighter was oriented such that the emitted X-rays propagated through the foil and were viewed normal to foil surface.

Optical quality smoothness was required on the target surface to perform the FDI measurements. The low cost of silicon wafers and the ability to readily etch silicon in a controlled manner made it an excellent choice for producing thin foil substrates for targets. This was achieved by coating $250 \AA$ of $\mathrm{Si}_{3} \mathrm{~N}_{4}$ on one side of a $500 \mu \mathrm{m}$ thick silicon wafer. After coating, a mask containing twelve $2 \times 2 \mathrm{~mm}$ square openings spaced by $500 \mu \mathrm{m}$ was placed on the silicon side of the wafer. Within each $2 \times 2 \mathrm{~mm}$ area, the exposed silicon was etched away completely, leaving only an optically flat $250 \AA \mathrm{Si}_{3} \mathrm{~N}_{4}$ window within each of the twelve $2 \times 2 \mathrm{~mm}$ square openings. The windows were next coated with $500 \AA$ of aluminum and $150 \AA$ of carbon on top of the aluminum, sandwiching the aluminum between the carbon and $\mathrm{Si}_{4} \mathrm{~N}_{3}$ to reduce the initial expansion. The back-lighter targets were coated with $1 \mu \mathrm{m}$ of samarium along the edge of a $50 \mathrm{~mm}$ long aluminum wedge. The samarium coated edge was placed 3 $\mathrm{mm}$ away from the rear surface of the foil target.

\section{Data and Analysis}

The phase shift data gathered with the FDI was used to determine the expansion velocity of the reflecting surface. Knowing the expansion velocity one can infer the density, temperture, and thickness of the absorbing layer by matching the experimental phase shifts to phase shifts calculated using hydrodynamic simulations performed using the 1-D hydrodynamic codes FILM[12] and LASNEX[13]. The expansion velocity, the transmitted and incident backlighter intensities, were measured on seperate shots where the laser intensity was simular. 


\subsection{Fourier Domain Interferometry}

Phase shift data obtained with the FDI diagnostic are displayed in Fig. 3. The time dependent phase of the reflected light was simulated using the hydrodynamics code FILM. The measured phase shift data for three shots are shown in Fig. 4. The measurements are compared with phase shift values calculated using FILM, showing very good agreement. The good agreement found with FILM deconvolved phase data suggest that the plasma follows the dynamics displayed in Fig. 5, where we show the temperature and density conditions as a function of time at the center of the foil. Further simulations were performed using the hydrodynamics code LASNEX. In Fig. 6 we show the corrsponding NLTE and LTE average ionization and the parameter $\Gamma_{i i}$. The simulations clearly show that the plasma departs from LTE at late times.

\subsection{X-ray Absorption Data}

The high sweep-speed and change in X-ray path length with dispersed energy produces a measurable difference in the arrival of the low and high energy Xrays. This effect is illustrated in Fig. 7, where we have illuminated the samarium back-lighter with the $300 \mathrm{fs}$ laser at low irradiance. When corrected, the result is a temporal sweep across the spectral range of interest. This effect limits the temporal window to $\approx 13$ ps that simultaneously contains O-like to Be-like charge states. In Fig. 8 we show typical data from the samarium backlighter. The back-lighter was generated using a $532 \mathrm{~nm}, 500$ ps pulse focused to $10^{15} \mathrm{~W} / \mathrm{cm}^{2}$. The spectral structure is dominated by M-shell unresolved transition array (UTA) emission. By post-processing hydrodynamic data from the code LASNEX with the atomic physics package STA (Super Transition Array)[14], the UTAs were identified as emission from the 4-3 manifolds of V-like samarium around $8.2 \AA$ and the 5-3 manifolds of $\mathrm{Ni}$-like, $\mathrm{Cu}$-like, and $\mathrm{Zn}$-like samarium. The temporal variation of the spectral window of strongest emission was found to be $20 \%$ over the duration recorded. The spectral structure was found to be consistant from shot to shot.

In Fig. 9, we show data plots at delays estimated as $0,4,8$ and 12 ps after the heating of the foil. For spectral smoothing, the reduced data was averaged over $750 \mathrm{fs}$. No timing fiducial was used on the streak camera so the heating time was estimated from the absorption features in the data. Due to uncertainty in the thermal background of the CCD, the absolute magnitude of the measured absorption could not be determined. At $t=0$, the O-like absorption feature has been clipped slightly due to the spectral sweep mentioned above. At this early period, the only features that are destinctive the data are those of the Be-like and Li-like charge states. The data clearly shows a significant amount of Be- 
nature of the experiment. Future experiments are planned for NLTE and LTE comparisons.

\section{Acknowledgment}

This work was performed under the auspices of the U.S. Department of Energy by University of California Lawrence Livermore National Laboratory under contract No. W-7405-Eng-48. One of us (M. F.) was financed through MCT (Portugal) under contract PRAXIS XXI/BBD/13732/97.

\section{References}

[1] Murnane MM, Kapteyn HC, Falcone RW. Phys Rev Lett 1989;62:155.

[2] Mancini R.C., et al. Phys Rev E 1996;54:4147.

[3] Eidmann K., et al. Jour. of Q.Spec Rad Trans 2000;65:173.

[4] Back C.A., Chenais-Popovics C., Renaudin P., Geindre J.P., Audebert P., Gauthier J.C. Phys Rev A 1992;46:3405.

[5] Perry T.S., et al. 1996;54:5617.

[6] Merdji H., et al. Phys Rev E 1998;57:1042.

[7] Fajardo M, et al. Phys Rev Lett 2001;86:1231.

[8] Strickland D, Mourou G. Opt Commun 1985;56:219.

[9] Rebibo, S et al. To be published.

[10] Blanc P., et al. J.O.S.A. B 1996;13:118.

[11] von Hamòs L., Z. Kristallogr. 1939;101:17.

[12] Teubner U., et al. Phys Plasmas 1996;3:2679.

[13] Zimmerman G, Kruer W. Comments Plasma Phys Controlled Fusion 1975;2:5.

[14] A. Bar-Shalom, J. Oreg,W.H. Goldstein,D. Shvarts, and A.Zigler, Phys. Rev. A 1989;40:3183

[15] Iglesias C., Rogers F. Astrophy. J 1996;464:943. 
Fig. 1. Layout for the experiment

Fig. 2. Setup geometry for the Fourier Domain Interferometry

Fig. 3. Deconvolved phase (in $\mathrm{S}$ and $\mathrm{P}$ polarizations) as a function of space along a diameter of the focal spot and time.

Fig. 4. Phase-shift data compared to simulation performed with FILM and spatially dependent conditions at $1 \mathrm{ps}$

Fig. 5. Time-dependent hydrodynamics of the central cell of the foil

Fig. 6. Comparison of NLTE and LTE average ionization and a plot of the NLTE $\Gamma_{i i}$.

Fig. 7. Streaked samarium spectrum heated with a 300 fs laser pulse at low energy. The high sweep-speed produces a sloped display due to the difference in the transit time of X-rays of different energies. This kind of shot was used to determine the time origin of streaked data.

Fig. 8. (Left) Typical data, after time distortion correction, from the time-resolved samarium back-lighter. (Right) Lineout of the spectrum between 7.6 and $8.2 \AA$.

Fig. 9. Measured transmission at four times and a comparison with the opacity code OPAL at $\mathrm{t}=12 \mathrm{ps}$ 


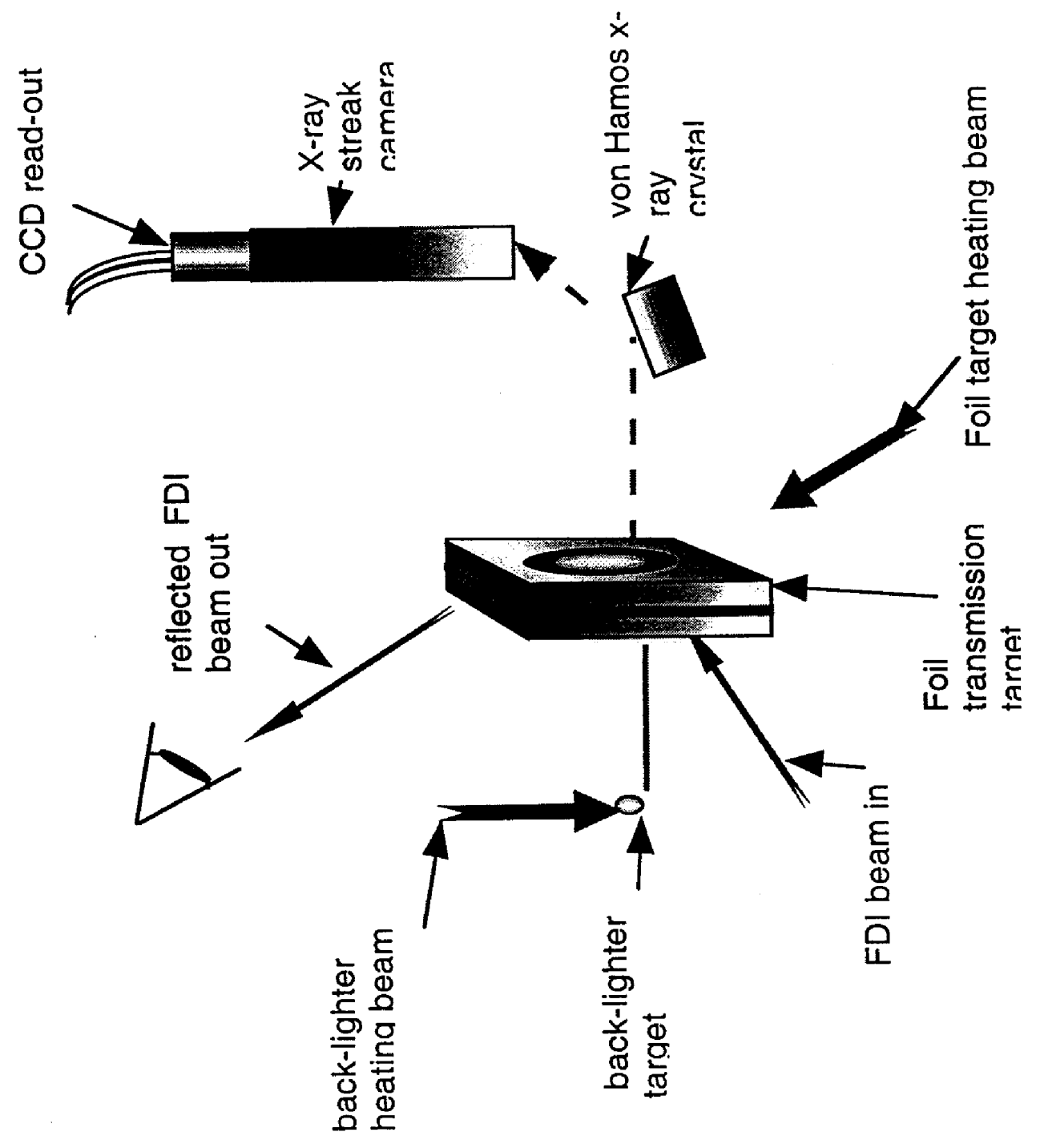




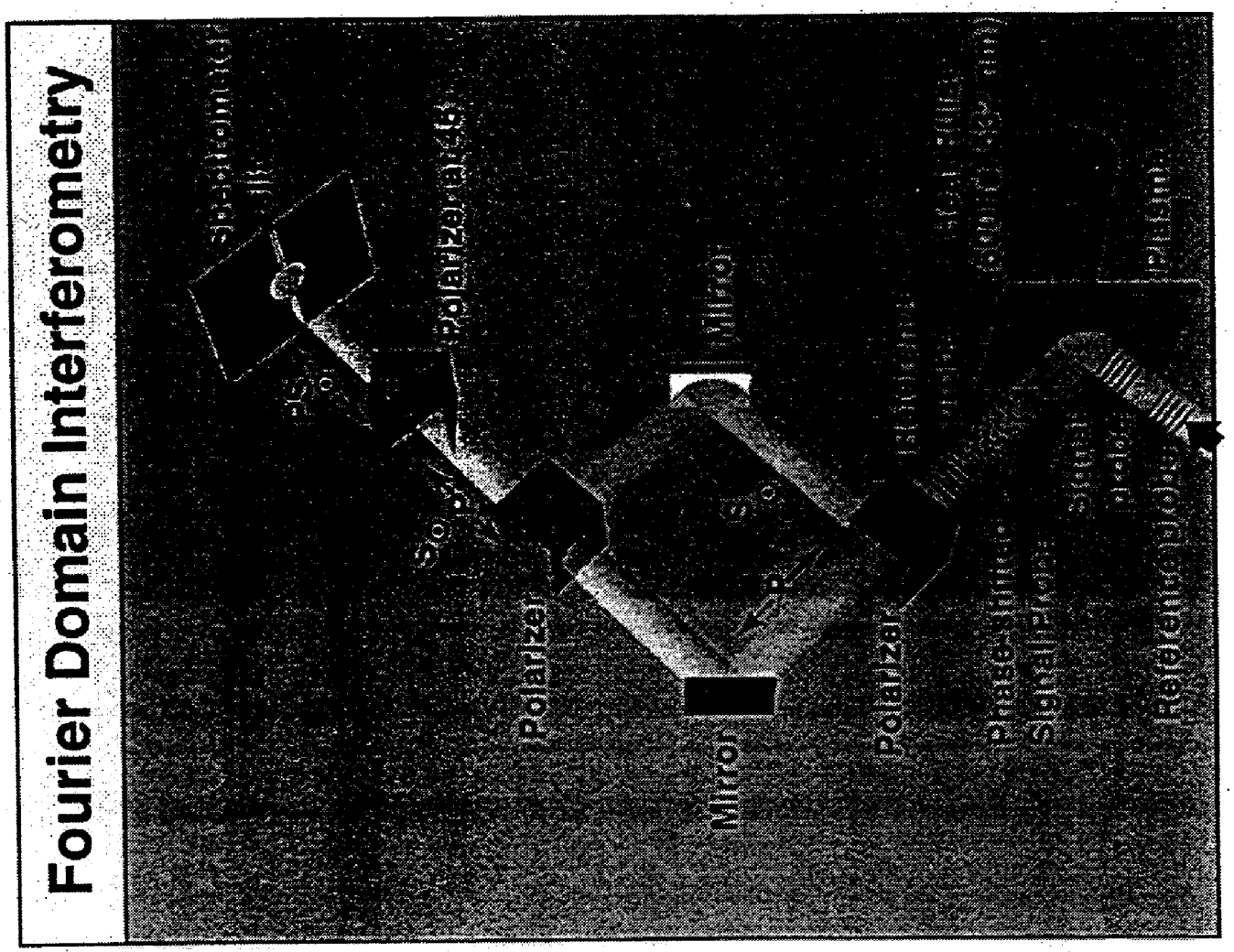




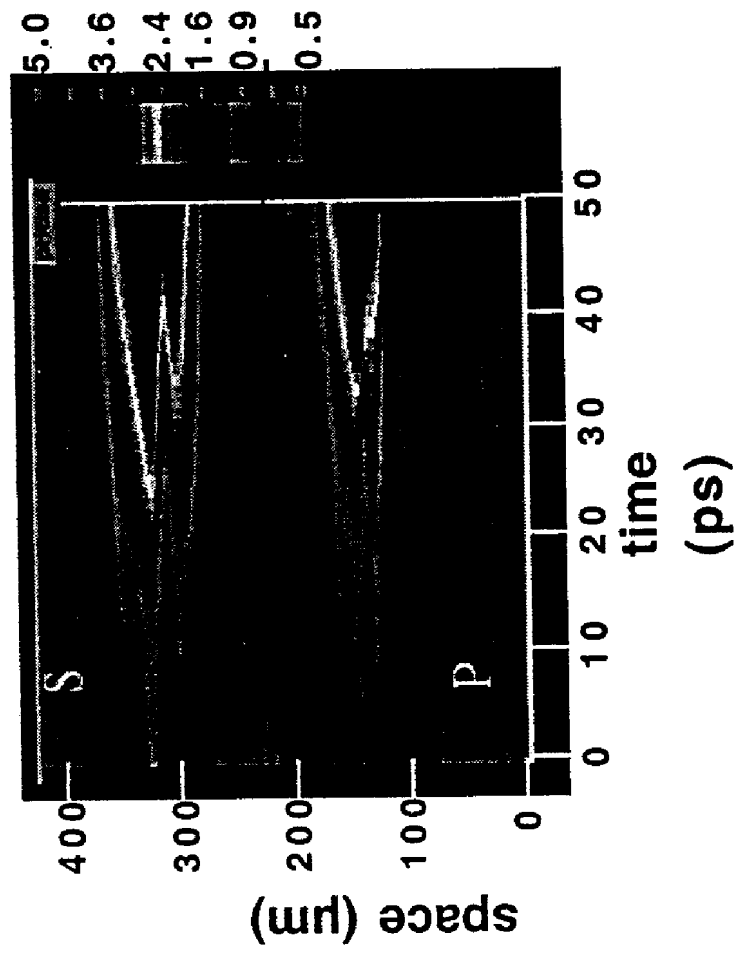



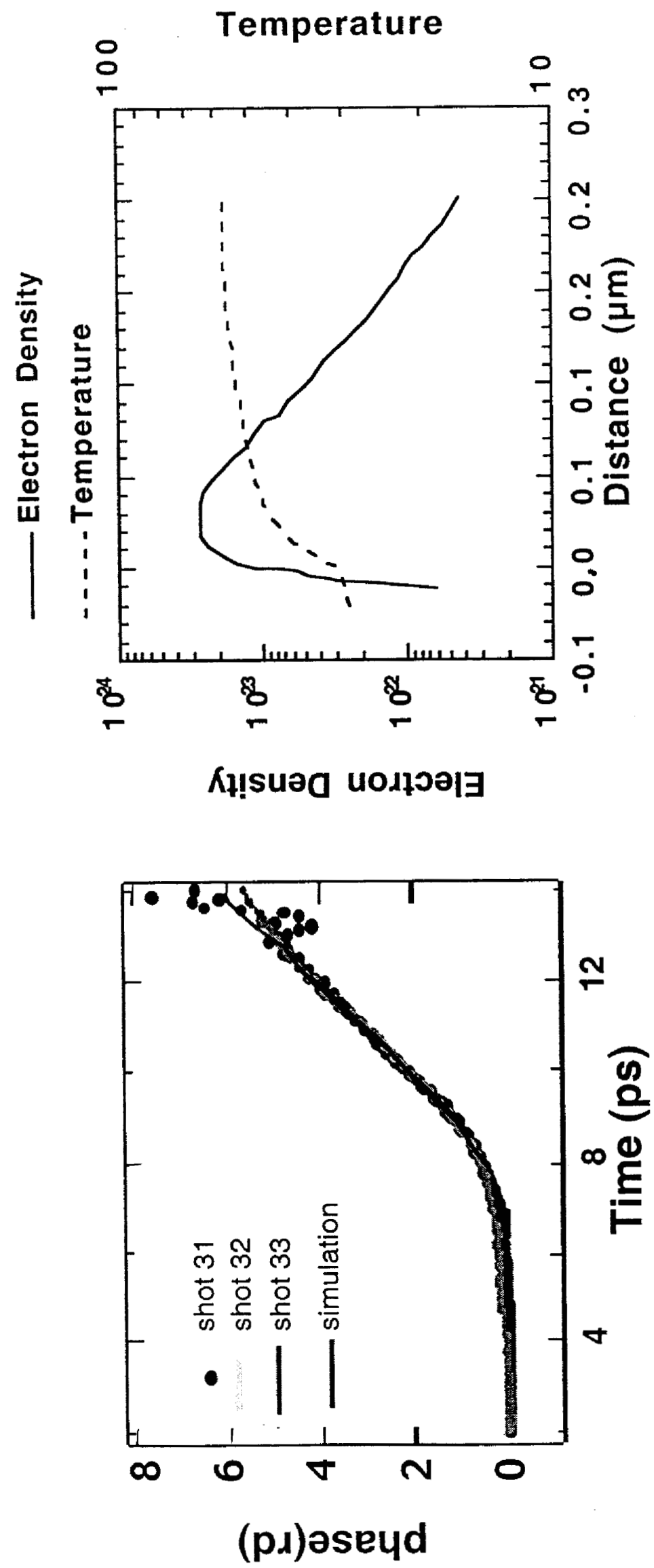


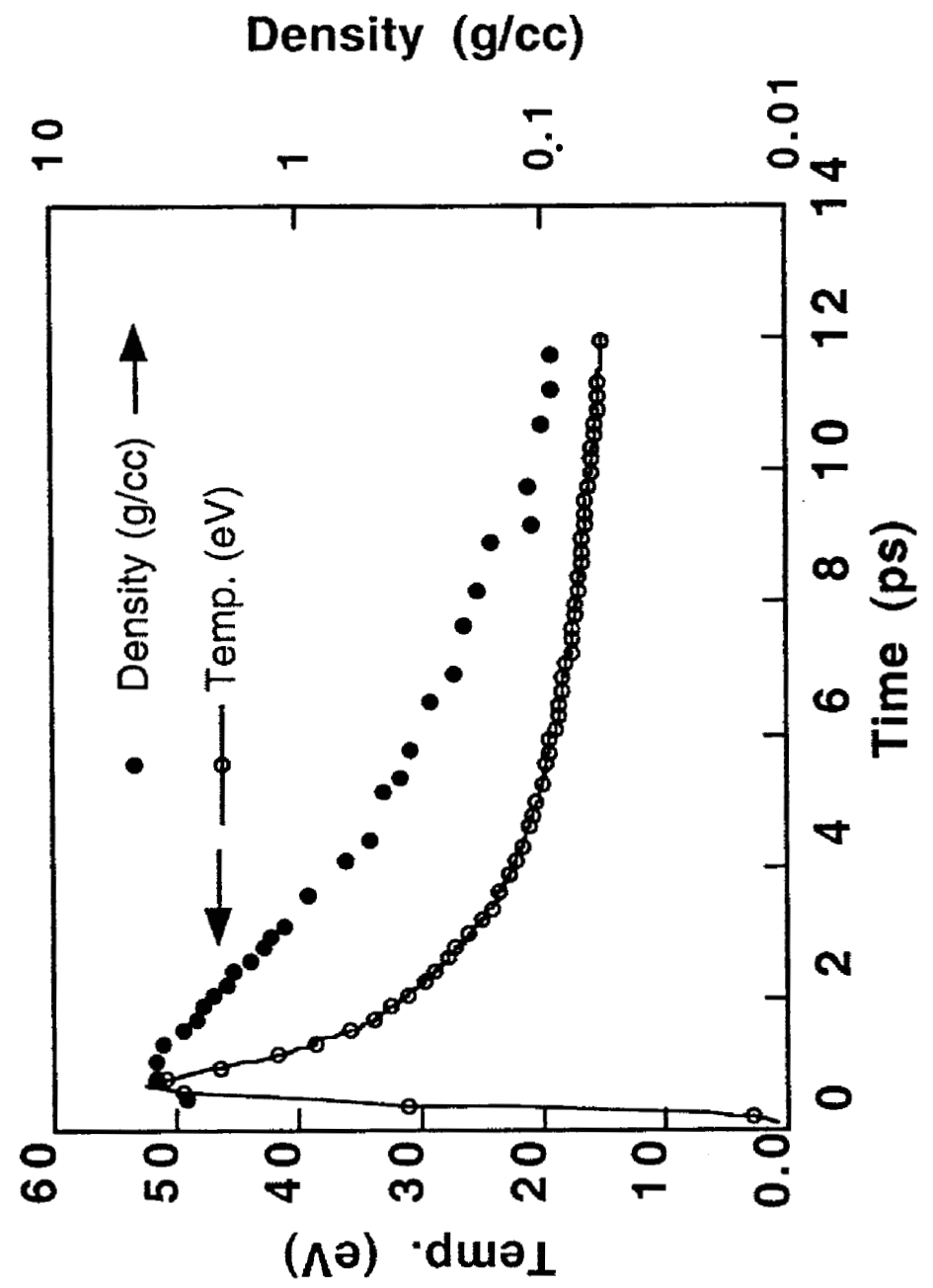




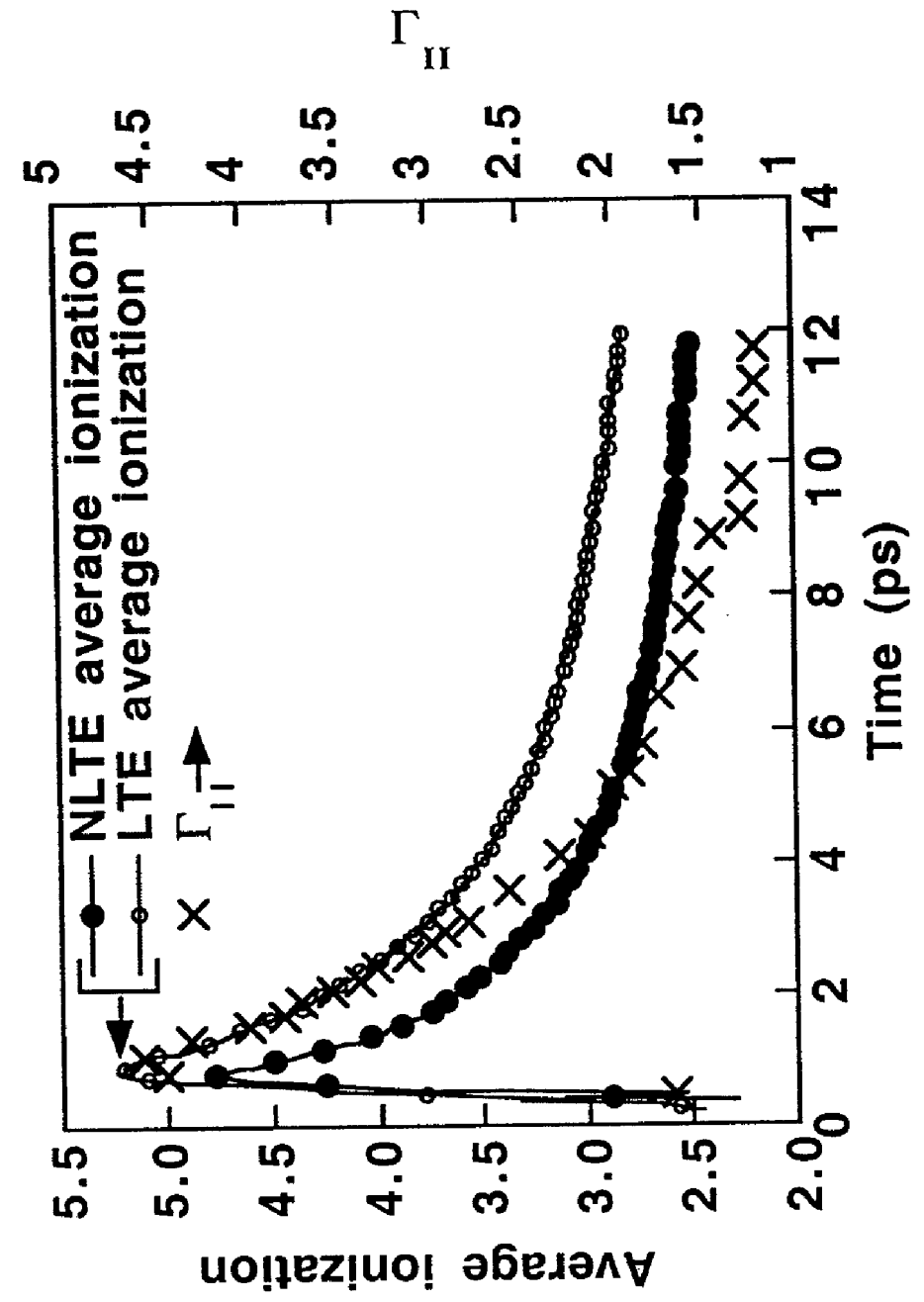




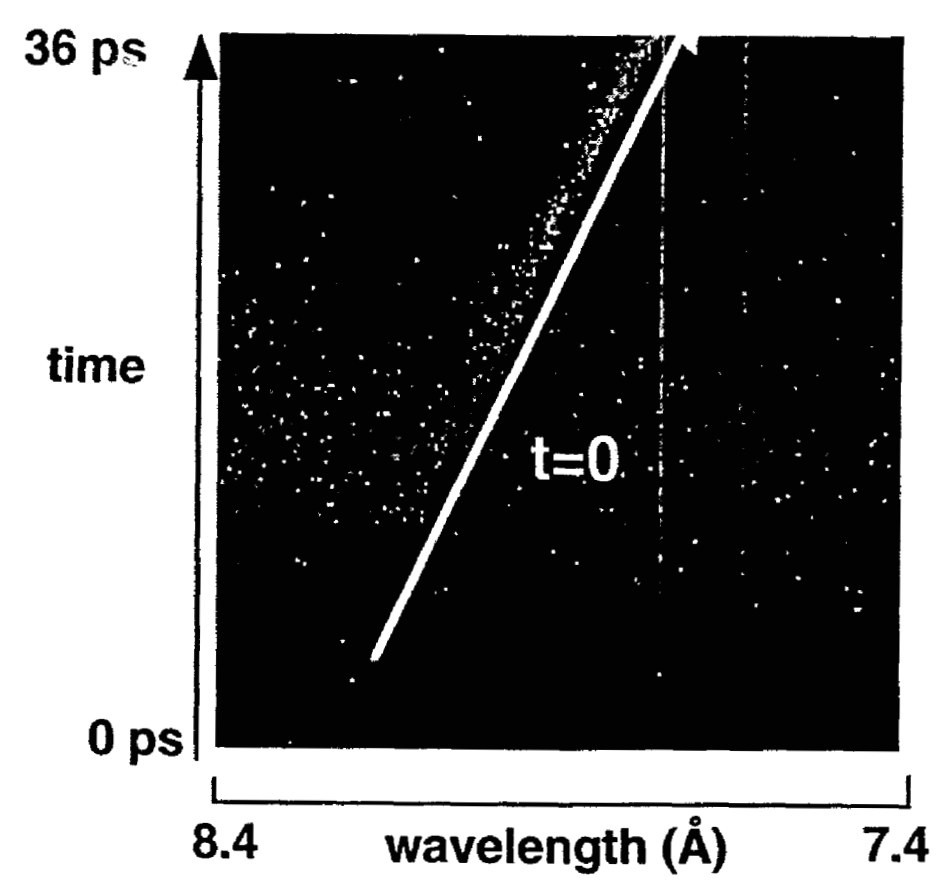




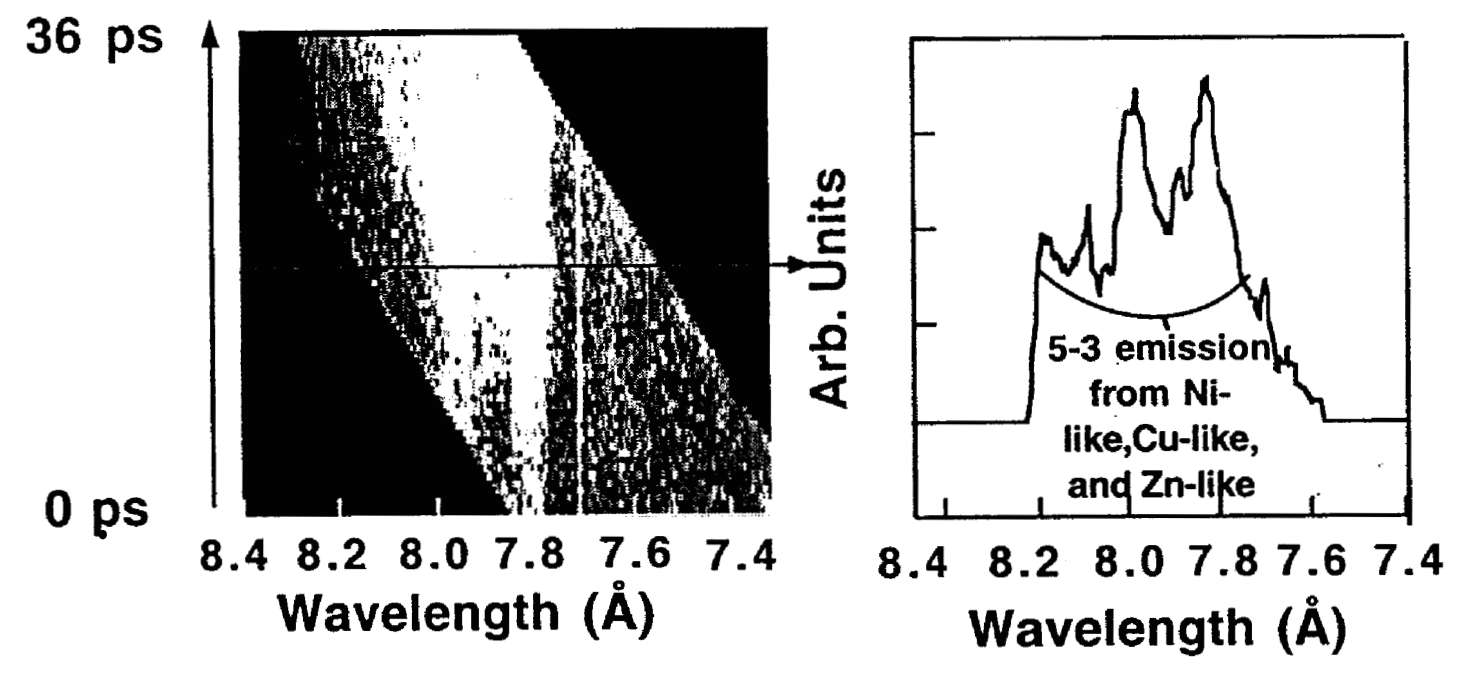



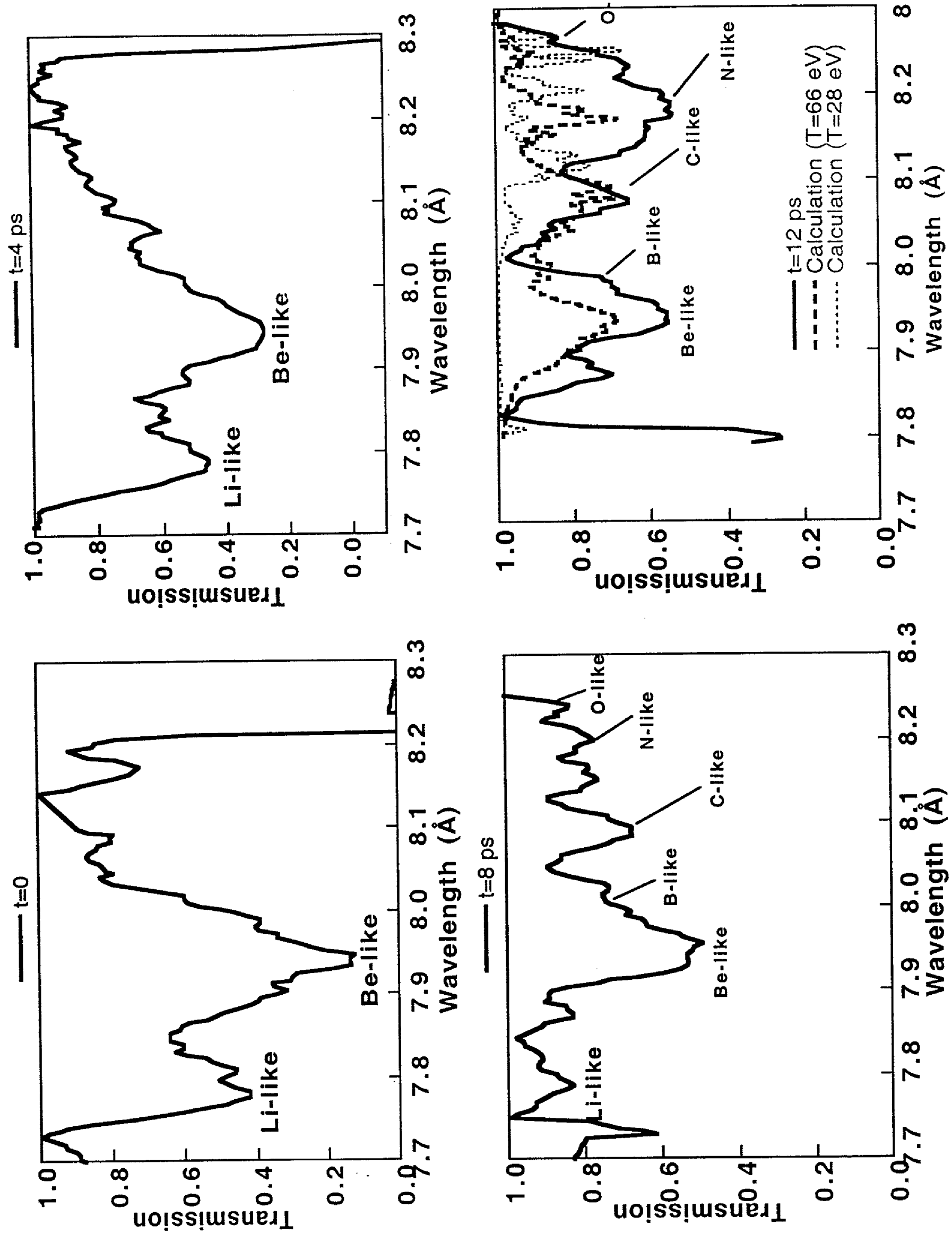